\title{
The Influence of Moisture Content on the Time-Dependent Characteristics of Rock Material and Its Application to the Construction of a Tunnel Portal
}

\author{
Xiaojun Liu, ${ }^{1}$ Chao Yang, ${ }^{2}$ and Jing Yu ${ }^{1}$ \\ ${ }^{1}$ School of Civil Engineering, Xian University of Architecture and Technology, Xian, Shaanxi 710055, China \\ ${ }^{2}$ China Merchants Chongqing Communications Research \& Design Institute Co., Ltd., Chongqing 400067, China \\ Correspondence should be addressed to Xiaojun Liu; liuyu8345@aliyun.com
}

Received 17 May 2015; Revised 10 September 2015; Accepted 10 September 2015

Academic Editor: Dimitrios G. Aggelis

Copyright (C) 2015 Xiaojun Liu et al. This is an open access article distributed under the Creative Commons Attribution License, which permits unrestricted use, distribution, and reproduction in any medium, provided the original work is properly cited.

Uniaxial compression creep experiments were carried out for low-grade metamorphic slate samples (located in the southeastern area of Guizhou province, China) with different moisture contents, using an Instron electric-fluid servo-compression machine. Based on the experimental results, a detailed analysis was made of the effect of moisture content on the strength and deformation behaviour of the slate specimens. The three-parameter generalised Kelvin model was identified to describe the creep behaviour of the low-grade metamorphic slate with different moisture contents. There is an approximately linear negative correlation between the elastic modulus and the saturation degree, and the viscoelastic modulus and viscosity coefficient show a negative exponent correlation with the saturation degree. The Kelvin creep model considering the moisture degradation effect was established and a three-dimensional finite difference model was developed with the software FLAC ${ }^{3 \mathrm{D}}$ to validate the creep model. A threedimensional numerical analysis was then performed to simulate the tunnel excavation process. The results show that the influence of moisture and creep of the surrounding rocks is needed for estimating the deformation of complex tunnel portals.

\section{Introduction}

The influence of moisture on the strength and deformability of rock has been analysed by many researchers [1-3]. Dyke and Dobereiner [4] demonstrated the variation in uniaxial compressive with moisture content for three quartz arenites ranging in dry strength from approximately 34 to $70 \mathrm{MPa}$. They concluded that in general the weaker the rock is, the more sensitive it is to changes in moisture content. Atkinson and Meredith [5] investigated experimentally the effect of water on subcritical microcrack growth parameters of granitic rocks. They found that the increase of humidity does not have a significant influence on the subcritical microcrack growth index $n$ but results in a large increase in microcrack growth velocity. Golshani et al. [6] checked the effect of moisture conditions on the time-dependent behaviour of Inada granite. The experimental and theoretical results have shown that the time-dependent behaviours of rocks are seriously affected by water $[7,8]$.
Tunnel entrance construction presents challenges and because of its complexity it could easily result in landslides or collapse [9-13]. Generally, the cover depth at the tunnel entrance is shallow as it often moves through a mountain surface layer whose rocks are usually broken and seriously weathered. So, the surrounding rocks at a tunnel portal are easily affected by surface water [14], which makes the rheological properties of surrounding rocks more obvious and involves many different complicated problems due to the uncertainty associated with the response of the rocks to the process of excavation and construction [15].

In this study, uniaxial compression creep experiments were carried out for the low-grade metamorphic slate samples (the surrounding rock of the Ruipo tunnel portal, which is located in the southeastern area of Guizhou province, China) with different moisture contents using an Instron electric-fluid servo-compression machine. A detailed analysis was made of the effect of moisture content on the strength and deformation behaviour of slate specimens. Then 


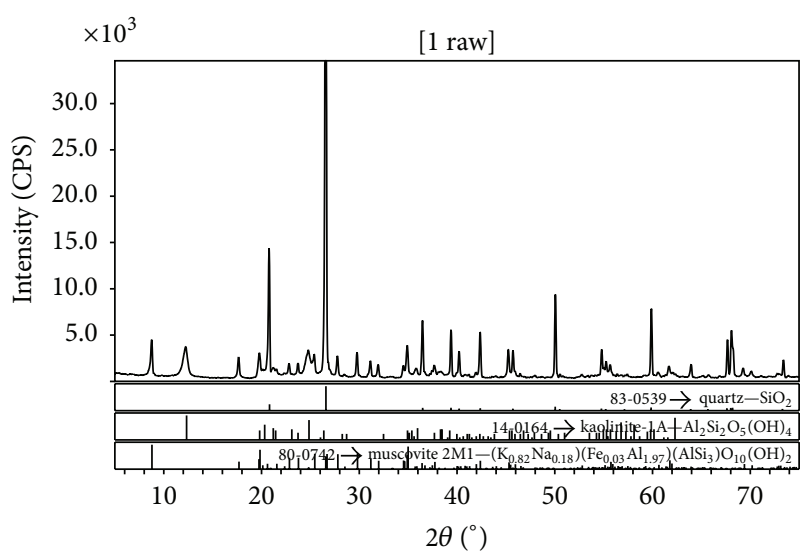

(a)

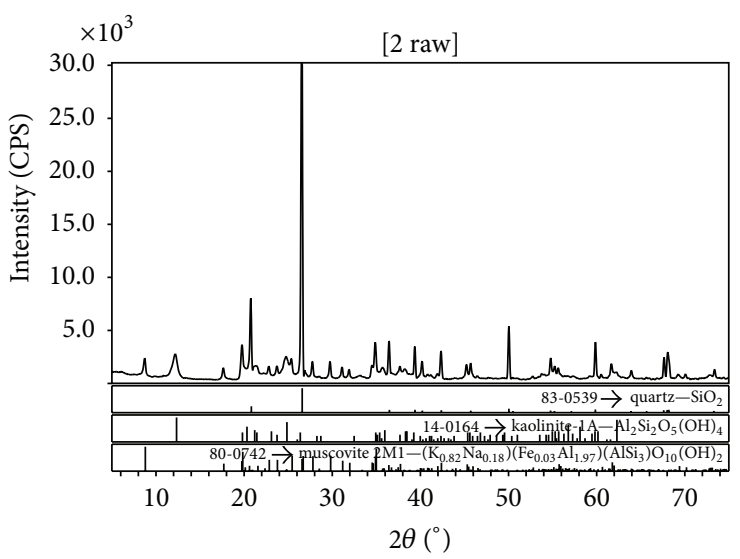

(b)

FIgURE 1: X-ray diffraction figures of low-grade metamorphic slate: (a) Specimen 1; (b) Specimen 2.

a three-dimensional finite difference analysis was executed on expressway tunnel portal areas while considering tunnel excavation and the moisture degradation effects on creep characteristics of surrounding rocks. In addition, the results were compared with those obtained by common elastoplastic models.

\section{Compression and Creep Tests}

2.1. Specimen Preparation and Experimental Procedure. Lowgrade metamorphic slate, a quintessential rock of the Shui-Du expressway that was taken from the Ruipo tunnel portal, has a cataclastic texture. X-ray diffraction analysis reveals that, apart from the most common quartz, kaolinite and muscovite are present in the collected low-grade metamorphic slate (see Figure 1). Kaolinite has a rough surface and perfect cleavage, strong water absorption, no water swelling, great plasticity in wet conditions, and a great influence on rock strength. There were 21 cylindrical test specimens, namely, S-1 to S21 , all $50 \mathrm{~mm}$ in diameter and $100 \mathrm{~mm}$ in length, which was in accordance with the tested sample size suggested by the ISRM [16]. Three degrees of saturation of specimens were considered for experiments and 6 specimens were prepared at each degree of saturation.

3 specimens, S-1, S-2, and S-3, were used to obtain the degree of saturation at different times. Nature dry specimens were considered as the first degree of saturation, specimens submerged in water for 24 hours represented the second degree, and those that remained submerged in water for 240 hours represented the third degree of saturation. The specimen preparation process was as follows. First, all specimens were nature-dried for 48 hours, the weights of S-1, S2 , and S-3 were measured, and S- 4 to S-9 were selected as the specimens at the first degree of saturation. Second, all specimens except S- 4 to S- 9 were submerged in water, and the weights of S-1, S-2, and S-3 were measured every 24 hours. After having been submerged in water for 24 hours, S-10 to S-15 were selected as the specimens at the second degree of saturation, and S-16 to S-21 were specimens at the third degree of saturation after having been submerged in water for 240

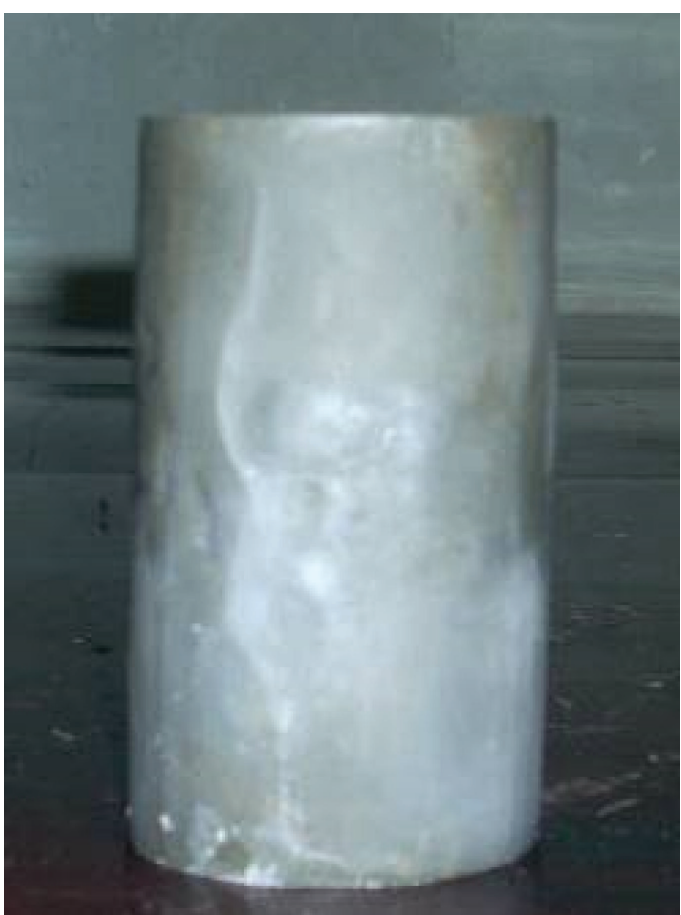

FIGURE 2: Specimen sealed up with wax.

hours. In order to avoid water loss from the specimens during compression testing, S-10 to S-21 were sealed up with wax (see Figure 2). Then, the dried weights of S-1, S-2, and S3 were obtained after having been oven-dried for 24 hours at $105^{\circ} \mathrm{C}$. Finally, S-1, S-2, and S-3 were saturated using the vacuum saturation method [17]. The samples were placed in the vacuum saturation apparatus and a sufficient amount of water at approximately $25^{\circ} \mathrm{C}$ was added to cover the sample. Entrapped air was removed from the samples by applying a residual manometer pressure of $100 \mathrm{kPa}$. The pressure was maintained for 4 hours and then the saturated weights of samples were measured. 


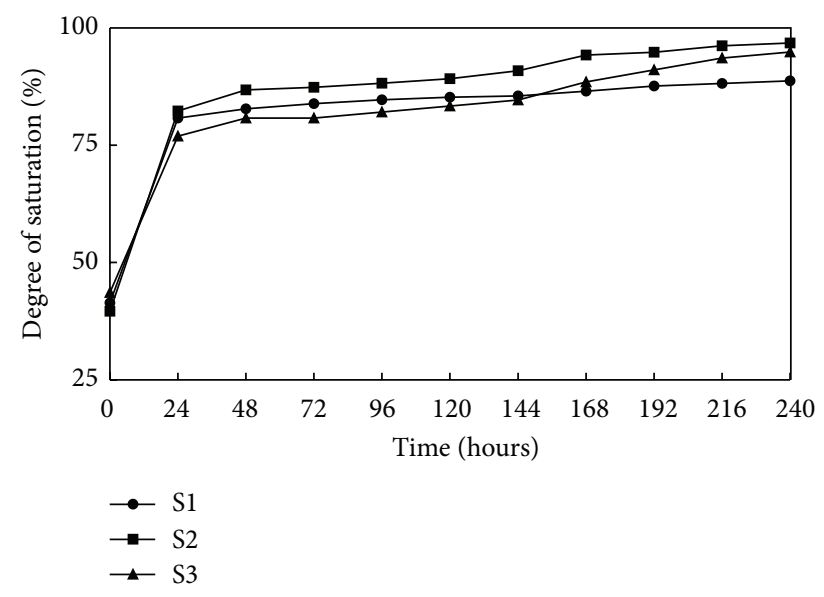

FIGURE 3: Curves showing relation between saturation degree of specimens and time submerged in water.

Uniaxial creep experiments were performed on an Instron 1346 electronic hydraulic servo-controlled testing machine, the loading capacity of which is $2 \mathrm{MN}$. Before the creep tests, uniaxial compression tests were performed on two specimens at each degree of saturation, and triaxial compression experiments were also carried out at each degree of saturation for specimens under three different confining pressures $\sigma_{3}$, that is, 2,5 , and $10 \mathrm{MPa}$. The instantaneous failure strengths and corresponding peak strains were obtained at failure of these specimens, and creep tests were planned from a knowledge of these values. The multilevel test was used: the load was applied at low levels, rising to a high level on the same specimen. The duration of tests was dependent on the displacement rates. In the case when the rate of displacement was less than $0.001 \mathrm{~mm} / \mathrm{h}$, the creep under this load level was considered to be basically stable [18]. The next load level could be executed afterwards, and the loading rating was $500 \mathrm{~N} / \mathrm{s}$.

\subsection{Experimental Results and Discussion}

2.2.1. Relationship between Saturation Degree and Time Submerged in Water. The degree of saturation of specimens at different times can be defined as

$$
S_{t}=\frac{m_{t}-m_{d}}{m_{s}-m_{d}} \times 100,
$$

where $m_{t}$ is the weight of the specimen after being soaked for a period of time; $m_{d}$ and $m_{s}$ are the dry weight and saturated weight of the specimen, respectively.

The experimental results showed that the degree of saturation increased with the time submerged in water (see Figure 3), and the average degrees of saturation of specimens were $41.5 \%, 80.1 \%$, and $93.5 \%$ when submerged in water for 0,24 , and 240 hours, respectively.

2.2.2. Mechanical Parameters Obtained from Uniaxial and Triaxial Compression Tests. Table 1 lists the mechanical parameters of specimens at three saturation degrees. The uniaxial compression strength of specimens with saturation degrees of $80.1 \%$ and $93.5 \%$ is, respectively, 69.85 and $58.74 \mathrm{MPa}$, which decreases by $24.2 \%$ and $36.2 \%$ compared with nature dry specimens, as well as the fact that elastic modulus has a reduction of $64.4 \%$ and $83.8 \%$ correspondingly. As a conclusion, a great decrease could be found in elastic modulus when compared with strength, and the increase of moisture causes an increase in Poisson's ratio.

For the triaxial test, the linear Mohr-Coulomb criterion, which can be expressed simply as a linear relationship between peak axial stress $\sigma_{1}$ and confining pressure $\sigma_{3}$, that is, $\sigma_{1}=\{(1+\sin \varphi) /(1-\sin \varphi)\} \sigma_{3}+2 c \cos \varphi /(1-\sin \varphi)$, is selected here to determine the peak strength parameters of cohesion $c$ and internal friction angle $\varphi$ [19]. The values of $c$ and $\varphi$ for the specimens in these tests decreased with the increase of saturation degree (see Figure 4). Several studies $[20,21]$ concluded that there was usually an exponential relation between the strength of rock material and moisture. The values of $c$ and $\varphi$ of the slate obtained by Li et al. [20] also had an exponential dependency on the rock moisture, and so the exponential function was chosen to describe the relationship between strength parameters and degree of saturation:

$$
\begin{aligned}
& c=32.12 e^{-0.0055 S,}, \\
& \varphi=39.68 e^{-0.0052 S,},
\end{aligned}
$$

where $S$ is the saturation degree of specimens (\%).

2.2.3. Creep Behaviour. Uniaxial experimental creep results for specimens are shown in Figure 5. Overall, transient and creep axial strains of the specimens increase with degree of saturation. At $\sigma_{1}=25.5 \mathrm{MPa}$, the transient axial strain of the three specimens was, respectively, $0.073 \%(S=41.5 \%)$, $0.074 \%(S=80.1 \%)$, and $0.413 \%(S=93.5 \%)$, and the axial strain of specimens increased by $0.003 \%, 0.026 \%$, and $0.066 \%$ correspondingly after creeping for 12 hours. At $\sigma_{1}=$ 35.7 MPa, the transient axial strain of the three specimens was, respectively, $0.092 \%$ ( $S=41.5 \%), 0.137 \%(S=80.1 \%)$, and $0.582 \%$ ( $S=93.5 \%$ ), and the axial strain of specimens increased by $0.003 \%, 0.080 \%$, and $0.041 \%$ correspondingly after creeping for 12 hours. When reaching the failure stress level, the specimens showed tertiary creep behaviour and succumbed to creep failure. The failure stress level of specimens was the highest while the saturation degree was $41.5 \%$ $(66.2 \mathrm{MPa})$ and then decreased when the moisture content was higher (56.1 and $38.2 \mathrm{MPa}$ for specimens with $S=80.1 \%$ and $93.5 \%)$.

From the compression and creep tests results, it can be seen that the moisture has a great effect on the strength and deformability of the low-grade metamorphic slate. Hawkins and McConnell [3] studied the sensitivity of sandstone strength and deformability to changes in moisture content. They concluded that the sensitivity increases progressively with higher proportions of clay minerals and rock fragments. 


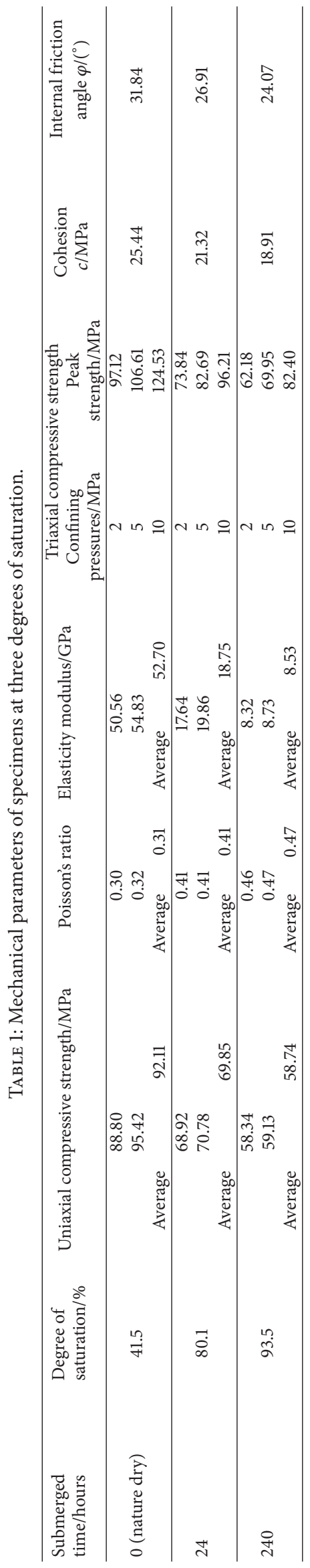




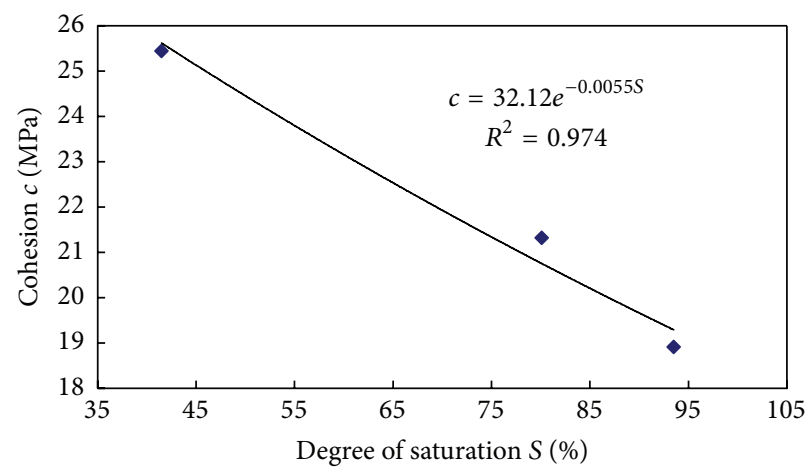

(a)

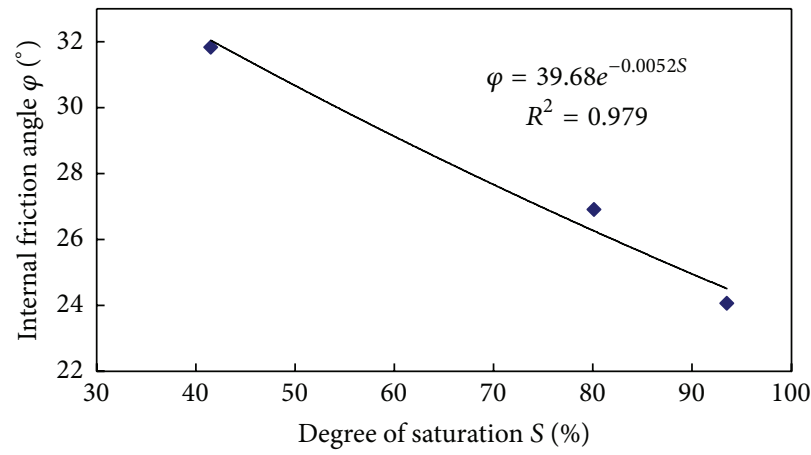

(b)

FIGURE 4: Relationships between the peak strength parameters and saturation degree of specimens: (a) $c-S$; (b) $\varphi-S$.

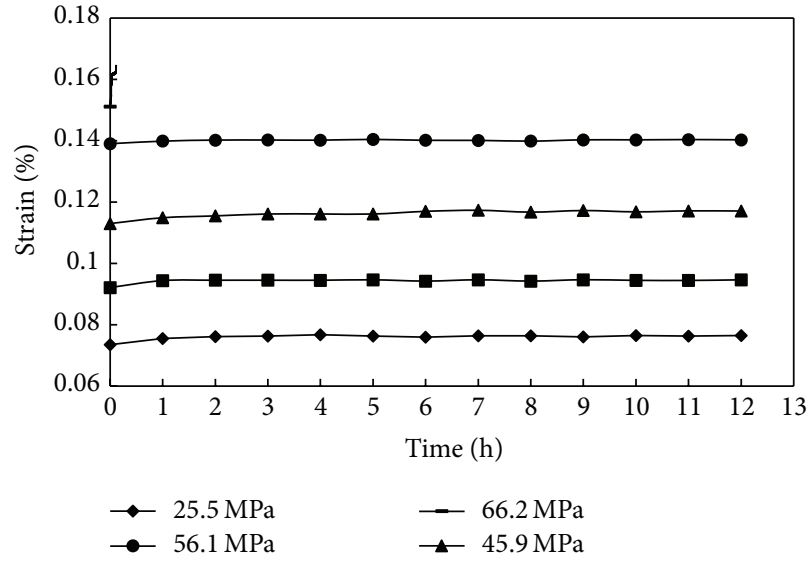

(a)

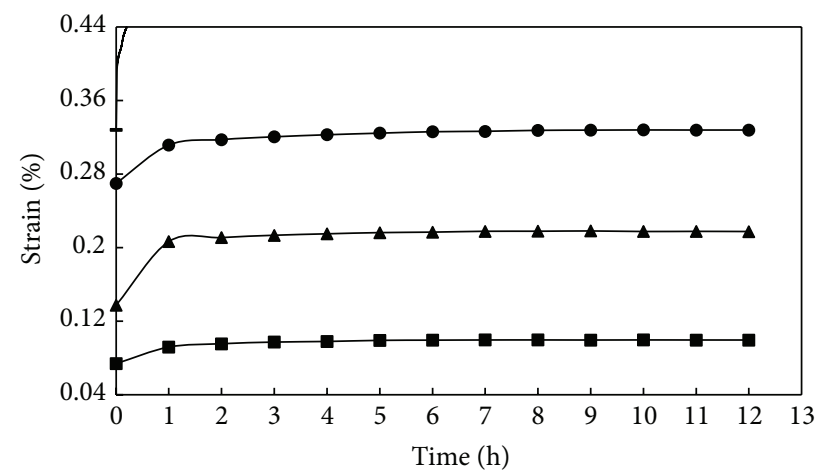

$\rightarrow-25.5 \mathrm{MPa}$

$\simeq 35.7 \mathrm{MPa}$

- $56.1 \mathrm{MPa}$

(b)

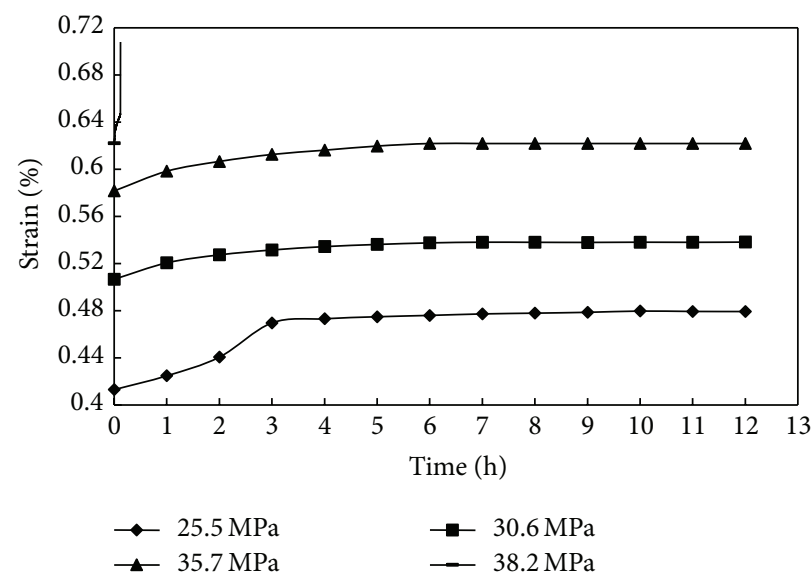

(c)

FIGURE 5: Curves showing relation between strain and time of specimens with different saturation degrees: (a) $S=41.5 \%$; (b) $S=80.1 \%$; (c) $S=93.5 \%$.

The low-grade metamorphic slate studied in this paper has $31 \%$ sericite and $10 \%$ siliceous cement, which have similar characteristics with clay minerals. Another important reason lies in the fact that the well-developed fissures might make it much easier for water to get into the rock specimens.

\section{Creep Model and Validation}

3.1. Creep Model considering Moisture Degradation Effect. From Figure 5, the deformation of specimens reached stability after a certain period of time and the strain rate reduced to zero. Therefore, the three-parameter generalised Kelvin 
TABLE 2: Creep parameters of specimens with different moisture contents.

\begin{tabular}{lcccc}
\hline Submerged time/hours & Degree of saturation/\% & Elastic modulus & Viscoelastic modulus & \multicolumn{2}{c}{$\begin{array}{c}\text { Viscosity coefficient } \\
E_{1} / \mathrm{GPa}\end{array}$} & 1536.43 & 2339.84 \\
\hline 0 (nature dry) & 41.5 & 39.01 & 148.60 & 229.78 \\
24 & 80.1 & 20.46 & 76.24 & 161.62 \\
240 & 93.5 & 6.20 & 24 \\
\hline
\end{tabular}

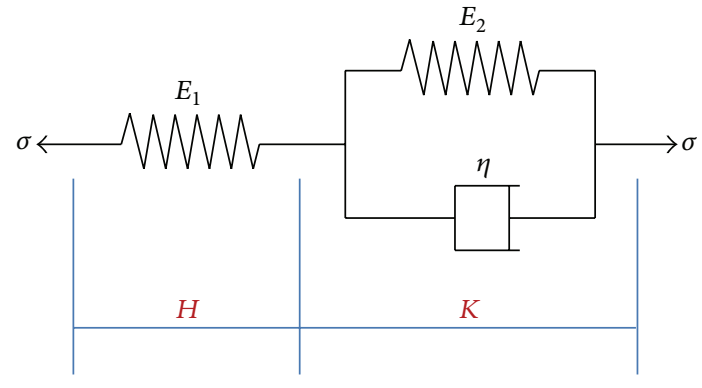

Figure 6: The three-parameter generalized Kelvin model.

model (see Figure 6), which connects in series an elastic component (Hookean body) and a Kelvin model, can be used to describe the deformation characteristics [22]. The onedimensional creep equation of the Kelvin model is

$$
\varepsilon=\frac{\sigma}{E_{1}}+\frac{\sigma}{E_{2}}\left(1-e^{-\left(E_{2} / \eta\right) t}\right),
$$

where $E_{1}, E_{2}$, and $\eta$ are the elastic modulus, the viscoelastic modulus, and the viscosity coefficient, respectively.

For the creep test, in general, the least square method is used to statistically process the test data [23]. The estimated creep parameters using the least square method are shown in Table 2 . There is an approximately linear negative correlation between the elastic modulus $E_{1}$ and the saturation degree $S$ (see Figure 7(a)):

$$
E_{1}=-0.5975 S+64.732 .
$$

The viscoelastic modulus $E_{2}$ and viscosity coefficient $\eta$ show a negative exponent correlation with saturation degree $S$ (see Figures 7(b)-7(c)):

$$
\begin{gathered}
E_{2}=17028 e^{-0.0584 S}, \\
\eta=20285 e^{-0.0533 S} .
\end{gathered}
$$

It can be seen that all the Kelvin model parameters, $E_{1}$, $E_{2}$, and $\eta$, decrease with the saturation degree. Therefore, the damage to the rock induced by water can be considered as the damage of each creep parameter. The damage variable of the elastic modulus $\left(D_{1}(S)\right)$ is defined as follows:

$$
D_{1}(S)=\frac{E_{1}(0)-E_{1}(S)}{E_{1}(0)},
$$

where $E_{1}(S)$ is the elastic modulus of rock with saturation degree $S$ and $E_{1}(0)$ is the elastic modulus of rock with saturation degree $S=0$. Substituting (4) into (6), we have

$$
D_{1}(S)=0.00923 S \text {. }
$$

In the same way, the damage variables of the viscoelastic modulus $\left(D_{2}(S)\right)$ and viscosity coefficient $\left(D_{3}(S)\right)$ can be described as follows:

$$
\begin{aligned}
& D_{2}(S)=\frac{E_{2}(0)-E_{2}(S)}{E_{2}(0)}=1-e^{-0.0584 S}, \\
& D_{3}(S)=\frac{\eta(0)-\eta(S)}{\eta(0)}=1-e^{-0.0533 S} .
\end{aligned}
$$

Substituting (7)-(8) into (3), the Kelvin creep model considering the moisture degradation effect can be expressed as

$$
\begin{aligned}
& \mathcal{\varepsilon}(t, S)=\frac{\sigma}{E_{1}(0)\left[1-D_{1}(S)\right]}+\frac{\sigma}{E_{2}(0)\left[1-D_{2}(S)\right]}(1 \\
& \left.-e^{-\left(E_{2}(0)\left[1-D_{2}(S)\right] / \eta(0)\left[1-D_{3}(S)\right]\right) t}\right) .
\end{aligned}
$$

3.2. Validation of the Creep Model. To validate the Kelvin creep model considering the moisture degradation effect, a three-dimensional finite difference model is developed with FLAC ${ }^{3 \mathrm{D}}$ [24]. In classical fluid mechanics there are the following three hypotheses [25]: (1) the creep deformation of rock material results from the partial stress tensor, but the spherical stress tensor does not cause the creep deformation; that is, no volume flow occurs during the creep deformation; (2) rock is a kind of isotropic material, and the shortterm stress-strain curve and creep curve in the tensile and compressive stress states are very similar; and (3) the Poisson's ratio of rock material is not dependent on time during the creep deformation. Based on the above hypotheses, we can derive the three-parameter generalised Kelvin model creep model in the three-dimensional stress state, which is described as follows:

$$
\varepsilon_{i j}=\frac{\sigma_{m} \delta_{i j}}{3 K}+\frac{S_{i j}}{2 G_{1}}+\frac{S_{i j}}{2 G_{2}}\left(1-\exp \left(-\frac{G_{2}}{\eta} t\right)\right)
$$

where $\varepsilon_{i j}$ is the strain tensor, $\sigma_{m}$ is the spherical stress tensor, $\delta_{i j}$ is the Kronecker delta, $S_{i j}$ is the partial stress tensor, $K$ is the bulk modulus, $G_{1}$ is the elastic shear modulus, and $G_{2}$ 


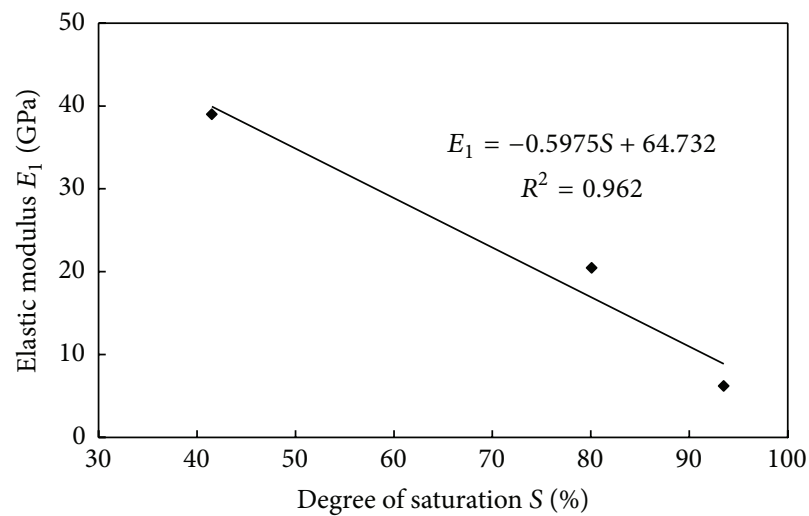

(a)

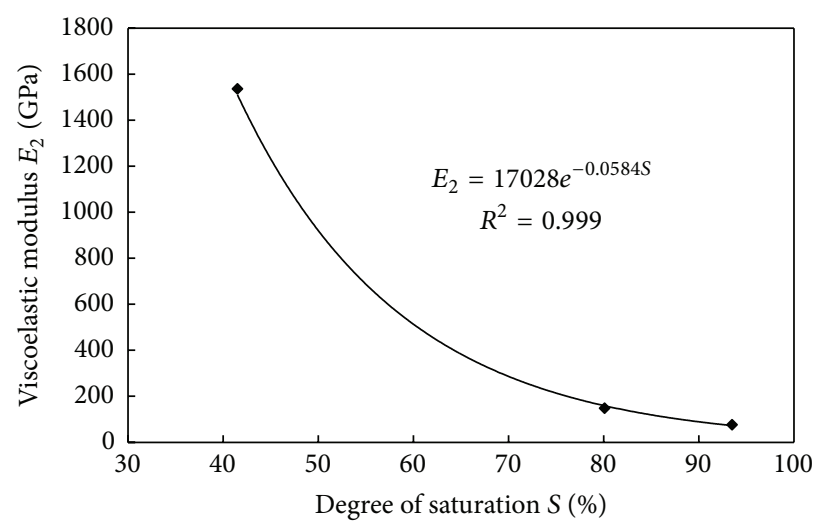

(b)

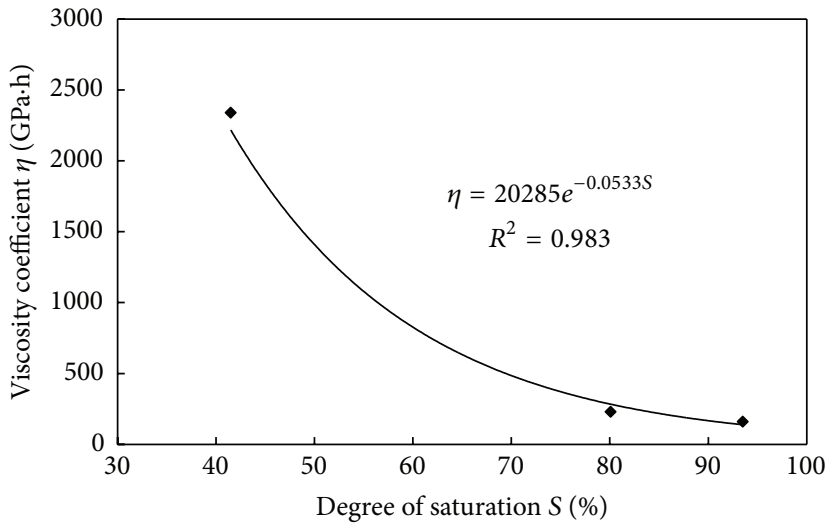

(c)

Figure 7: Parameters of generalized Kelvin model with the degrees of saturation: (a) $E_{1}-S$; (b) $E_{2}-S$; (c) $\eta-S$.

is the viscoelastic shear modulus. In the three-dimensional space, we can obtain the following equations:

$$
\begin{aligned}
\sigma_{m} & =\frac{1}{3}\left(\sigma_{1}+\sigma_{2}+\sigma_{3}\right), \\
S_{i j} & =\sigma_{i j}-\sigma_{m} \\
K & =\frac{E_{1}}{3(1-2 \mu)}, \\
G_{1} & =\frac{E_{1}}{2(1+\mu)}, \\
G_{2} & =\frac{E_{2}}{2(1+\mu)} .
\end{aligned}
$$

Due to the limitations of the Kelvin model in dealing with the plastic characteristic of rock material, a MohrCoulomb model is then used. The viscoelastic and plastic strain rate components are assumed to act in series. The viscoelastic constitutive law corresponds to the Kelvin model, and the plastic constitutive law corresponds to the MohrCoulomb model. The creep model is developed by using a user subroutine, which is an option provided by FLAC ${ }^{3 \mathrm{D}}$. The shape and size of the finite difference model are the same as for the tested specimens, and the mesh contains 1,000 elements and 1,111 nodes. The parameter values in the model are obtained from the laboratory test.

The calculated results for the specimens are shown in Figure 8. Although there is a certain deviation, the calculated curves coincide basically with the experimental curves with the same general rules, which demonstrates the validity of the creep model when considering the moisture degradation effect.

\section{An Application of Three-Dimensional Analysis of the Ruipo Tunnel Portal}

4.1. Project Background. The Shui-Du (Shuikou to Duyun city in Guizhou province, China) expressway is one of the most difficult sections in the construction of the Xiamen to Chengdu highway, which is the number 16 east-west expressway of the National Trunk Highway System. 58 tunnels were designed on the Shui-Du expressway, with a total length of $71,988 \mathrm{~m}$ (34.6\% of the whole line) and more than 200 tunnel portals. Almost all of the rocks surrounding the tunnel portals are broken and have poor stability. About half of the portals are shallow buried and unsymmetrically loaded, such as the Laozhai tunnel portal [26] and the Ruipo tunnel portal (see Figure 9). Another challenge was the rainy season that set in during the excavation of tunnel portals. The heavy and constant rainfall would lead to a serious decrease in 


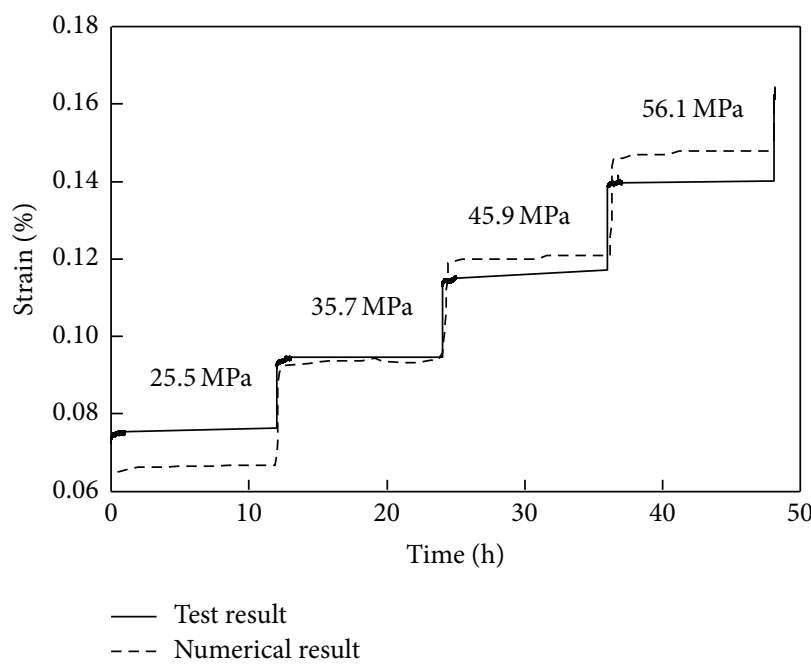

(a)

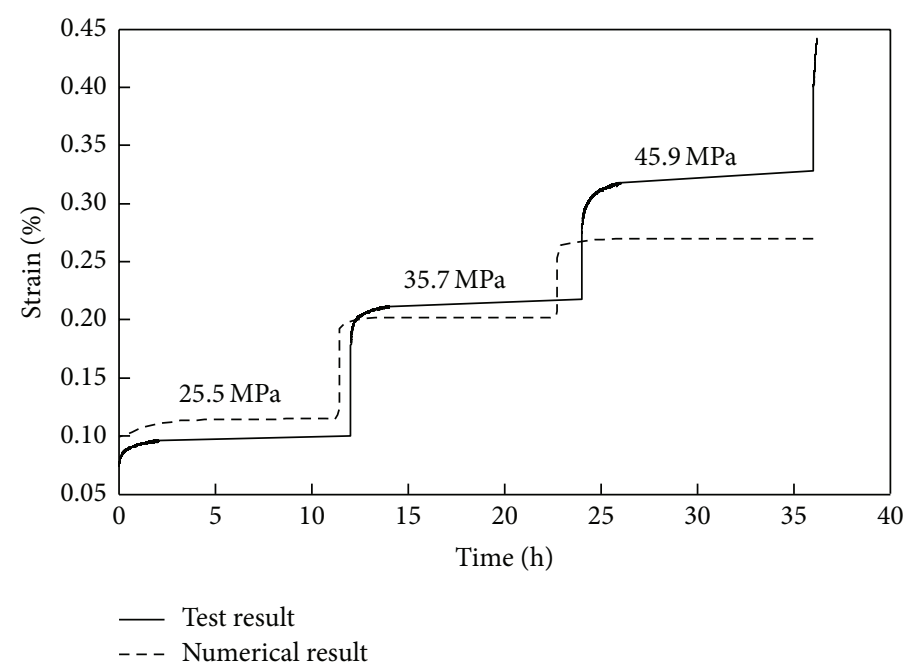

(b)

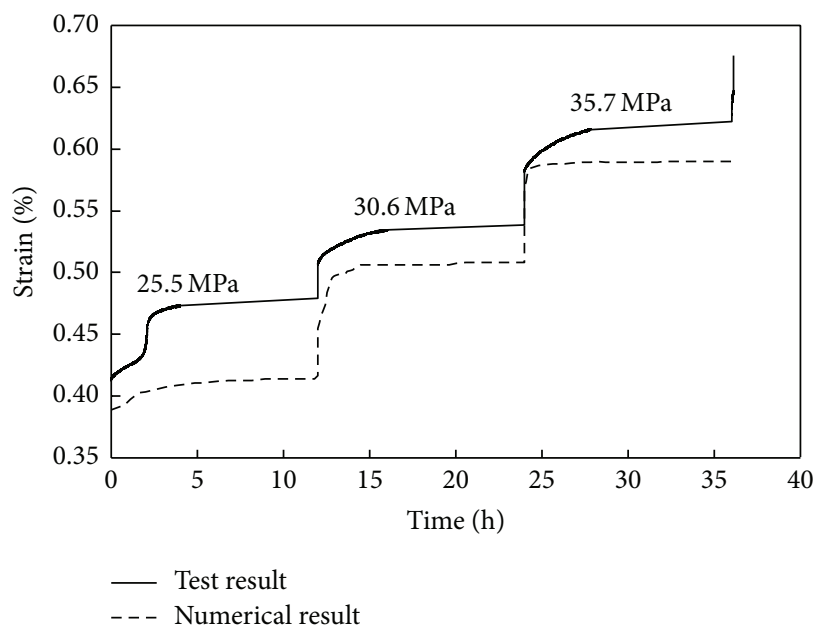

(c)

FIGURE 8: Comparison between numerical data and laboratory test data of specimens with different saturation degrees: (a) $S=41.5 \%$; (b) $S=80.1 \%$; (c) $S=93.5 \%$.

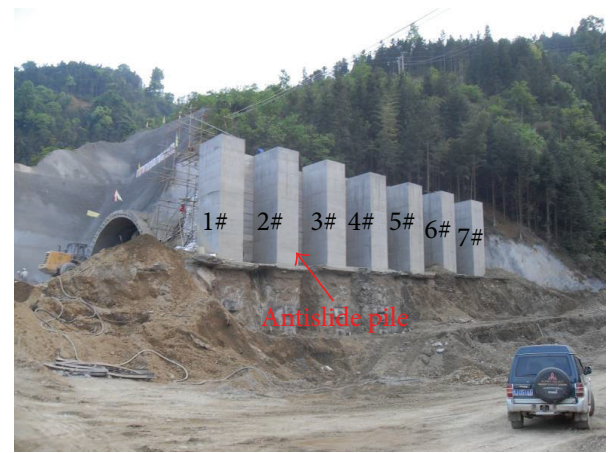

FIGURE 9: Ruipo tunnel portal on the Shui-Du expressway.

surrounding rock quality. In order to overcome the difficulties in excavation, many prereinforcements (such as retaining wall and antislide pile) were built before excavation. Also, many complicated excavation methods, for example, the cross diaphragm (CRD) method [27] and ring-like drift heading method [28], were adopted. The excavation was slow (less than $2 \mathrm{~m} / \mathrm{d}$ ), but even then collapse occurred in many tunnel portals.

The Ruipo tunnel is located in AT11 section of the Shui-Du expressway, with starting and ending milestones of ZK49+865 and ZK51+395. The surrounding rocks of the tunnel portal section (ZK49+865 and ZK50+000) were composed mainly of strong-weathered slate and completely weathered slate, which have very poor stability. The tunnel portal section was seriously shallow buried (the depth was $0-38 \mathrm{~m}$ ) and unsymmetrically loaded (the transversal gradient was about $40^{\circ}$ ). According to design, the excavation in the tunnel portal section was to be performed by the CRD method. Before excavation the surrounding rocks were reinforced by a grouting method and a $108 \mathrm{~mm}$ diameter steel pipeline shed was installed along the tunnel outline, for which the intervals of steel were $50 \mathrm{~cm}$. In order to mitigate the 


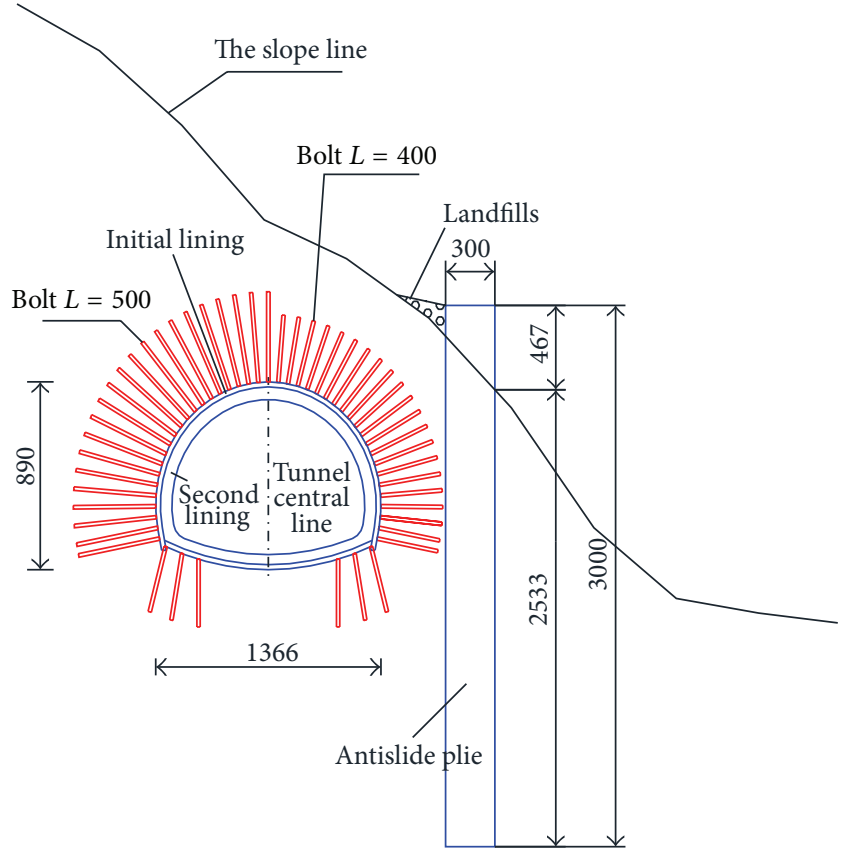

(a)

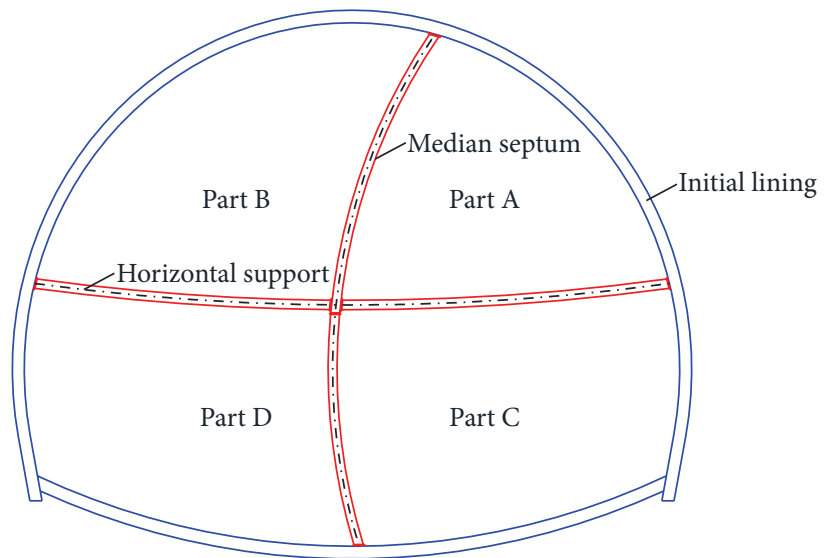

(b)

FIGURE 10: The support system and excavation sequence: (a) support system at ZK49+899; (b) excavation sequence with CRD method (length unit: $\mathrm{cm}$ ).

influence of an unsymmetrical load, seven antislide piles were installed in the shallow buried side. The support system and excavation sequence are shown in Figure 10.

During excavation rain began to fall and lasted for nearly 3 days, and then the portal suffered severe damage. Cracks first appeared in the slope, initial support, and landfills behind the antislide piles, and more cracks appeared and spread in the next few days (see Figure 11). For the reason that damage happened shortly after the tunnel portal excavation, only the forces of antislide piles were measured. The monitoring results are shown in Figure 12 (many measurements were not picked up for the reason that the earth pressure cells were destroyed). As can be seen in Figure 12, the maximum value of the forces was only $55 \mathrm{kPa}$; the low forces showed that antislide piles had less reinforcement effect. The reason for this is that the rainfalls reduced the loading capacity of the surrounding rocks and landfills in the shallow buried side, which could not transmit the unsymmetrical pressure from the deep buried side to the antislide piles.

4.2. Elements and Boundary Conditions. In order to analyse the moisture degradation effect on creep characteristics of surrounding rocks, a three-dimensional finite difference analysis was performed by using the program FLAC ${ }^{3 \mathrm{D}}$. The analysis model includes information from the horizontal direction, 5.5 times the tunnel span from the tunnel centre to the model boundary, and from the vertical direction, 3 times the tunnel height from the tunnel bottom to the base boundary, and from the height above the tunnel from the tunnel crown to the nature ground surface. The model dimensions $(x, y$, and $z$ ) were approximately $143 \mathrm{~m}, 71 \mathrm{~m}$, and $72 \mathrm{~m}$. The boundary conditions include a free ground surface, fixed left and right boundaries in the $x$-axis direction, fixed front and rear boundaries in the $z$-axis direction, and a fixed base boundary in the $y$-axis direction. The tunnel liners, steel pipeline shed, horizontal support, and median septum are modelled with shell elements, and the antislide piles are modelled with solid elements. There are 63,519 elements in this numerical model (see Figure 13).

4.3. Simulation Phases and Rock Mass Physical and Mechanical Properties. Before excavation, the system was brought to elastic equilibrium (time 0 of modelling) under gravity. Boundary and initial conditions were set. Referring to Figure 9, the excavation sequence can be defined for the CRD method as follows.

Stage 1. Part A was excavated once with a length of $2 \mathrm{~m}$.

Stage 2. Parts A and B were excavated once with lengths of $2 \mathrm{~m}$.

Stage 3. Parts A, B, and C were excavated once with lengths of $2 \mathrm{~m}$.

Stage 4. Parts A, B, C, and D were excavated once with lengths of $2 \mathrm{~m}$, until the tunnel excavation was completed.

Based on the actual situation of tunnel excavation and support implementation, no matter which part was excavated, the lining and anchors corresponding to that part should be activated before the creep time of 12 hours had 


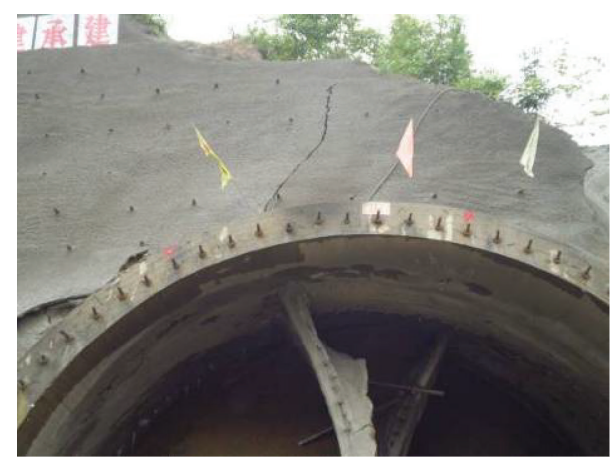

(a)

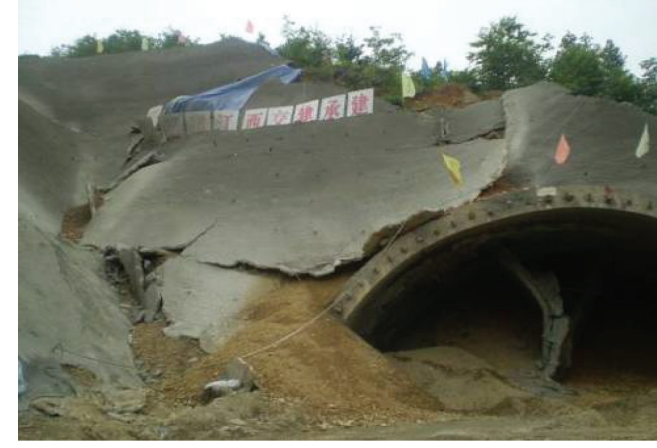

(b)

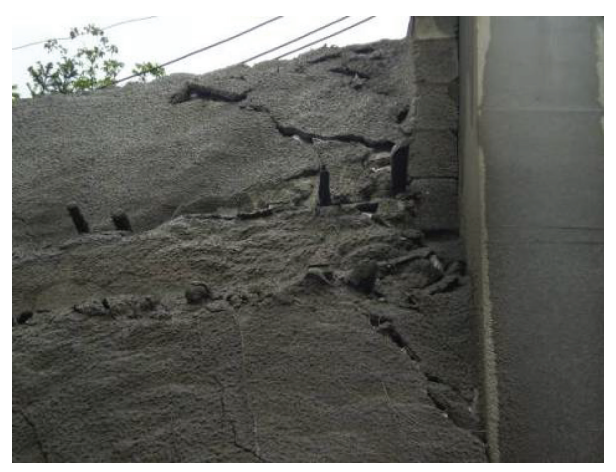

(c)

FIGURE 11: Damage in Ruipo tunnel portal: (a) cracks in slope at the beginning; (b) cracks expanded and instability of the slope; (c) cracks in landfills behind the antislide pile.

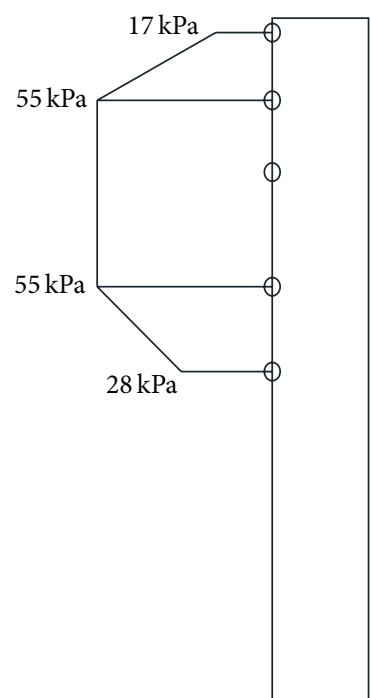

(a)

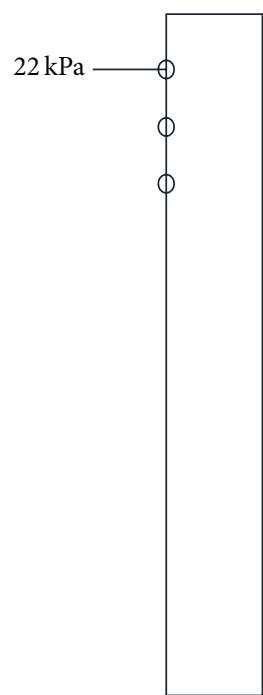

(b)

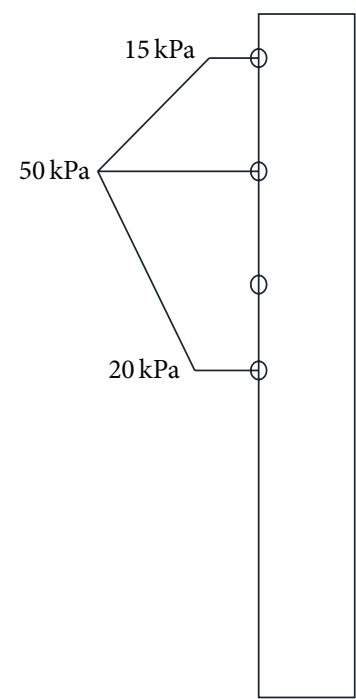

(c)

Figure 12: Measurement results of pressure between landfills and antislide piles: (a) 2 \# antislide pile; (b) 4 \# antislide pile; (c) 6 \# antislide pile.

passed. And the next excavation stage was performed 24 hours after the support implementation.

For comparison, another condition, where the influences of rainfall and creep were not considered, was also simulated. The lining and anchors corresponding to the excavated part should be activated simultaneously to simulate the support of the tunnel.

The constitutive models used in the numerical calculation are as follows: elastic model for all of the support system, including the tunnel liners, steel pipeline shed, horizontal 
TABle 3: Physical and mechanical properties of the rock mass and support.

\begin{tabular}{|c|c|c|c|c|c|c|}
\hline Properties & $\begin{array}{l}\text { Strong-weathered } \\
\text { slate }\end{array}$ & $\begin{array}{l}\text { Completely weathered } \\
\text { slate }\end{array}$ & Initial lining & Second lining & Antislide pile & Landfills \\
\hline Bulk volume $\gamma /\left(\mathrm{kN} / \mathrm{m}^{3}\right)$ & 23 & 18 & 22 & 25 & 25 & 22 \\
\hline Elastic modulus/MPa & $2.28 E+03$ & $9.62 E+02$ & $2.40 E+04$ & $3.25 E+04$ & $3.25 E+04$ & $2.10 E+04$ \\
\hline Poisson's ratio & 0.35 & 0.4 & 0.2 & 0.2 & 0.2 & 0.2 \\
\hline Cohesion $c / \mathrm{MPa}$ & 0.25 & 0.10 & - & - & - & - \\
\hline Friction angle $\varphi /^{\circ}$ & 30 & 20 & - & - & - & - \\
\hline $\begin{array}{l}\text { Elastic bulk modulus } \\
K / \mathrm{MPa}\end{array}$ & 327.1 & 32.3 & - & - & - & - \\
\hline $\begin{array}{l}\text { Elastic shear modulus } \\
G_{1} / \mathrm{MPa}\end{array}$ & 158.5 & 15.2 & - & - & - & - \\
\hline $\begin{array}{l}\text { Viscoelastic shear } \\
\text { modulus } G_{2} / \mathrm{MPa}\end{array}$ & 6108.1 & 593.4 & - & - & - & - \\
\hline $\begin{array}{l}\text { Viscosity coefficient } \\
\eta /(\mathrm{MPa} \cdot \mathrm{h})\end{array}$ & 9072.3 & 889.0 & - & - & - & - \\
\hline
\end{tabular}

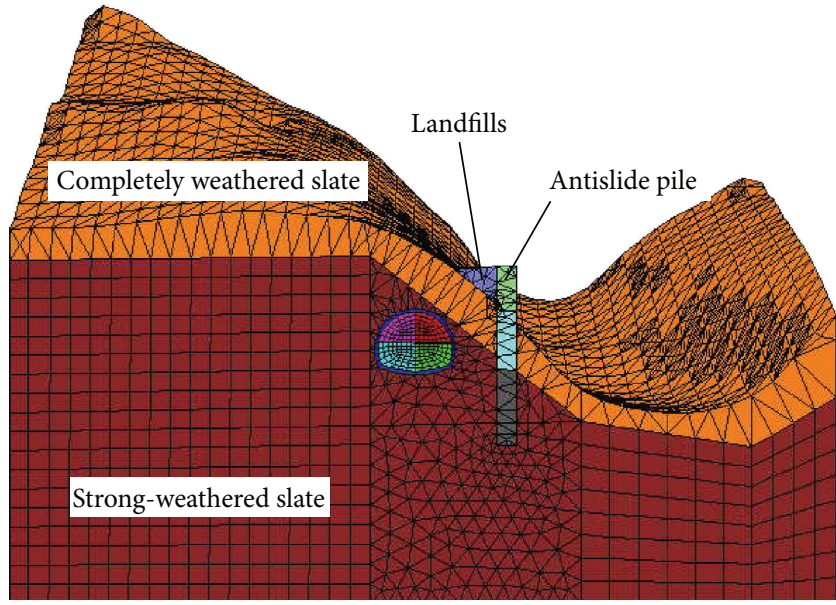

FIGURE 13: Three-dimensional analysis model.

support, median septum, and antislide piles; the Kelvin-MC model established in Section 4.1 for surrounding rocks; and the Mohr-Coulomb model for surrounding rocks under the condition that the influences of rainfall and creep were not considered.

The evaluation of the rock mass quality has been carried out through detailed geomechanical field surveys according to the ISRM suggested method [29]. The geological strength indexes of the strong-weathered slate and completely weathered slate are 25 and 10, respectively. The results obtained by field surveys and laboratory tests allowed us to apply the Hoek-Brown failure criterion and estimate the rock mass strength and elastic properties [30]. The decreases in the rock mass uniaxial compression strength were used to estimate the creep properties of rock mass [31]. The rock mass and support physical and mechanical properties are listed in Table 3.

During excavation, a heavy rainfall lasted for 3 days. Based on the relationship between saturation degree and time submerged in water (Section 2.2.1), the saturation degree of rock mass was estimated to be $84.0 \%$.
4.4. Simulation Results. The excavation section ZK49+883, which was in the middle portion of the freshly constructed tunnel, was chosen as the subject for the research. Large surface subsidence happened after ZK49+883 was excavated (see Figure 14); the maximum value for the vertical displacement was $-791 \mathrm{~mm}$. The unsymmetrical surface subsidence squeezed the tunnel support structure, which made downward vertical displacements on the deep buried side and upward vertical displacements in the arch foot and haunch of shallow buried side. The maximum value for the horizontal displacement of surrounding rocks near the tunnel was $36 \mathrm{~mm}$, which lies in the haunch of the deep buried side. The horizontal displacement of landfills behind the antislide piles was also very large. The simulation results show an acceptable agreement with the real situation.

The vertical and horizontal displacements at section ZK49+883, where the influences of rainfall and creep were not considered, are shown in Figure 15. The maximum values for the vertical and horizontal displacements were $7.2 \mathrm{~mm}$ and $2.1 \mathrm{~mm}$, respectively. The low displacements indicate that the tunnel excavation is safe under this condition.

\section{Conclusions}

In this study, laboratory experiments were performed to understand the compression and creep characteristics of the low-grade metamorphic slate with different moisture states. Then a three-dimensional analysis on the Ruipo tunnel portal was performed while considering tunnel excavation and the moisture degradation effect on creep characteristics of surrounding rocks. The laboratory tests showed that the moisture has a great effect on the strength and deformability of the low-grade metamorphic slate, and the mathematical relation between the creep parameters and degree of saturation was established. The simulation results show that the tunnel excavation is safe without considering the influence of rainfall and creep, whereas with these being considered large surface subsidence and displacement would appear. Therefore, a three-dimensional analysis that considers the 

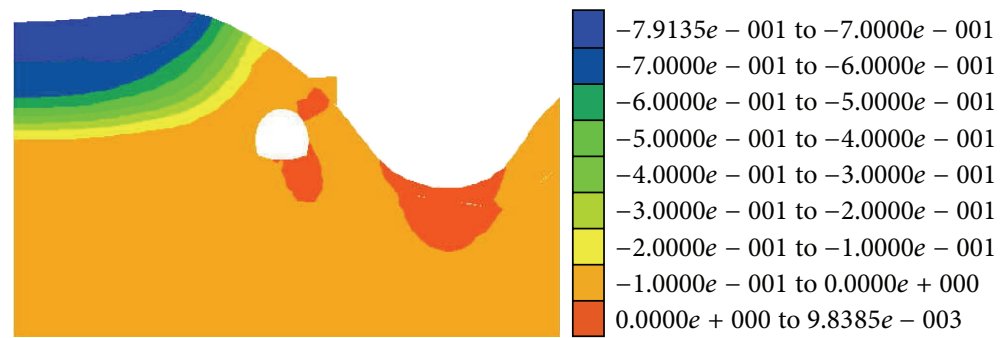

(a)

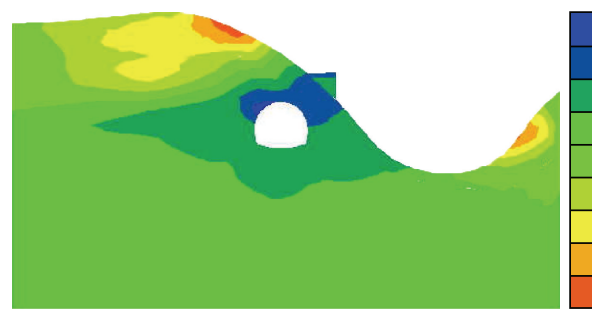

$-3.6114 e-002$ to $-3.0000 e-002$ $-3.0000 e-002$ to $-2.0000 e-002$ $-2.0000 e-002$ to $-1.0000 e-002$ $-1.0000 e-002$ to $0.0000 e+000$ $0.0000 e+000$ to $1.0000 e-002$ $1.0000 e-002$ to $2.0000 e-002$ $2.0000 e-002$ to $3.0000 e-002$ $3.0000 e-002$ to $4.0000 e-002$ $4.0000 e-002$ to $4.9421 e-002$

(b)

FIGURE 14: Displacements at section ZK49+883 when the influences of rainfall and creep were considered: (a) vertical displacement; (b) horizontal displacement.

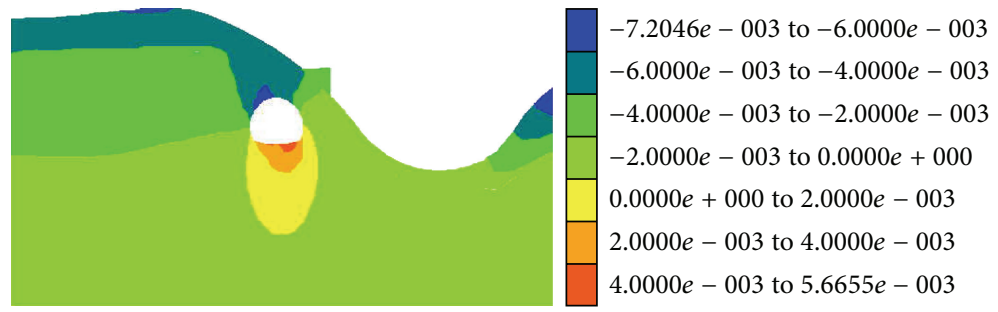

(a)

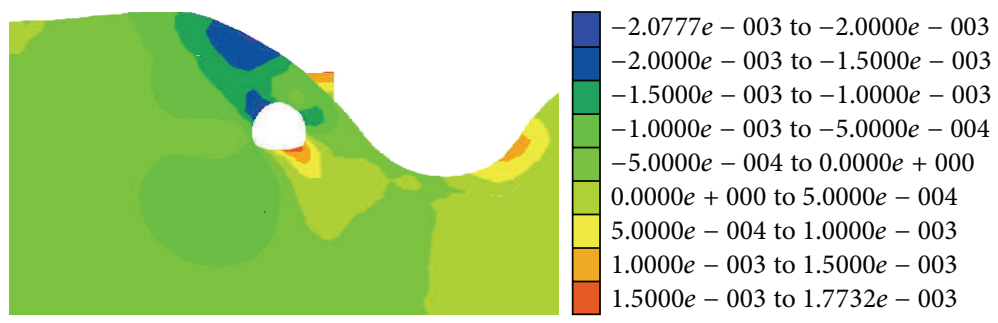

(b)

FIGURE 15: Displacements at section ZK49+883 when the influences of rainfall and creep were not considered: (a) vertical displacement; (b) horizontal displacement.

influence of moisture and creep of the surrounding rocks is needed for estimating the deformation of complex tunnel portals.

\section{Conflict of Interests}

The authors declare that there is no conflict of interests regarding the publication of this paper.

\section{Acknowledgments}

This work is supported by the National Natural Science Foundation of China (no. 51408464), the Foundation of
Shaanxi Educational Committee (no. 14JK1413), and the Foundation for the Talents of Xian University of Architecture and Technology (no. RC1365).

\section{References}

[1] L. S. Burshtein, "Effect of moisture on the strength and deformability of sandstone," Soviet Mining Science, vol. 5, no. 5, pp. 573$576,1969$.

[2] E. M. van Eeckhout and S. S. Peng, "The effect of humidity on the compliances of coal mine shales," International Journal of Rock Mechanics and Mining Sciences and, vol. 12, no. 11, pp. 335340, 1975. 
[3] A. B. Hawkins and B. J. McConnell, "Sensitivity of sandstone strength and deformability to changes in moisture content," Quarterly Journal of Engineering Geology, vol. 25, no. 2, pp. 115130, 1992.

[4] C. G. Dyke and L. Dobereiner, "Evaluating the strength and deformability of sandstones," Quarterly Journal of Engineering Geology, vol. 24, no. 1, pp. 123-134, 1991.

[5] B. K. Atkinson and P. G. Meredith, "The theory of subcritical crack growth with applications to mineral and rocks," in Fracture Mechanics of Rock, Academic Press, London, UK, 1987.

[6] A. Golshani, M. Oda, Y. Okui, T. Takemura, and E. Munkhtogoo, "Numerical simulation of the excavation damaged zone around an opening in brittle rock," International Journal of Rock Mechanics and Mining Sciences, vol. 44, no. 6, pp. 835-845, 2007.

[7] E. Z. Lajtai, R. H. Schmidtke, and L. P. Bielus, "The effect of water on the time-dependent deformation and fracture of a granite," International Journal of Rock Mechanics and Mining Sciences \& Geomechanics Abstracts, vol. 24, no. 4, pp. 247-255, 1987.

[8] P. G. Meredith and B. K. Atkinson, "Stress corrosion and acoustic emission during tensile crack propagation in Whin Sill dolerite and other basic rocks," Geophysical Journal International, vol. 75, no. 1, pp. 1-21, 1983.

[9] P. A. Vermeer, S. C. Möller, and N. Ruse, "On the application of numerical analysis in tunnelling," in Proceedings of the 12th Asian Regional Conference on Soil Mechanics and Geotechnical Engineering, Singapore, August 2003.

[10] M. Karakus and R. J. Fowell, "An insight into the New Austrian Tunneling Method (NATM)," in Proceedings of the 7th Regional Rock Mechanics Symposium (ROCKMEC '04), Sivas, Turkey, October 2004.

[11] H. Gercek, "Underground space use: analysis of the past and lessons for the future," in Three-Dimensional Regions in Tunnels, S. Erdem, Ed., Taylor \& Francis Group, London, UK, 2005.

[12] Z. Z. Wang, B. Gao, Y. J. Jiang, and S. Yuan, "Investigation and assessment on mountain tunnels and geotechnical damage after the Wenchuan earthquake," Science in China Series E: Technological Sciences, vol. 52, no. 2, pp. 546-558, 2009.

[13] T. B. Li, "Damage to mountain tunnels related to the Wenchuan earthquake and some suggestions for aseismic tunnel construction," Bulletin of Engineering Geology and the Environment, vol. 71, no. 2, pp. 297-308, 2012.

[14] F. Ye, C. He, S.-M. Wang, and J.-L. Zhang, "Landscape design of mountain highway tunnel portals in China," Tunnelling and Underground Space Technology, vol. 29, pp. 52-68, 2012.

[15] Y.-W. Pan and J.-J. Dong, "Time-dependent tunnel convergence-I. Formulation of the model," International Journal of Rock Mechanics and Mining Sciences \& Geomechanics Abstracts, vol. 28, no. 6, pp. 469-475, 1991.

[16] C. E. Fairhurst and J. A. Hudson, "Draft ISRM suggested method for the complete stress-strain curve for intact rock in uniaxial compression," International Journal of Rock Mechanics and Mining Sciences, vol. 36, no. 3, pp. 281-289, 1999.

[17] J. Mills-Beale, Z. You, R. C. Williams, and Q. L. Dai, "Determining the specific gravities of coarse aggregates utilizing vacuum saturation approach," Construction and Building Materials, vol. 23, no. 3, pp. 1316-1322, 2009.

[18] Y. S. Li and C. C. Xia, "Time-dependent tests on intact rocks in uniaxial compression," International Journal of Rock Mechanics and Mining Sciences, vol. 37, no. 3, pp. 467-475, 2000.

[19] S.-Q. Yang and H.-W. Jing, "Strength failure and crack coalescence behavior of brittle sandstone samples containing a single fissure under uniaxial compression," International Journal of Fracture, vol. 168, no. 2, pp. 227-250, 2011.

[20] C. Y. Li, H. L. Fu, H. L. Cai, X. N. She, and C. L. Nie, "Water character of flowering sheet stone," Journal of Railway Science and Engineering, vol. 6, no. 1, pp. 74-77, 2009 (Chinese).

[21] H. Lin, J. G. Deng, L. B. Hu, J. L. Yuan, Z. J. Chen, and X. D. Lai, "Study on the effect of water content on rock strength and sand production," Science Technology and Engineering, vol. 13, no. 13, pp. 3710-3713, 2013 (Chinese).

[22] W.-D. Yang, Q.-Y. Zhang, S.-C. Li, and S.-G. Wang, "Estimation of in situ viscoelastic parameters of a weak rock layer by timedependent plate-loading tests," International Journal of Rock Mechanics and Mining Sciences, vol. 66, pp. 169-176, 2014.

[23] W. Korzeniowski, "Rheological model of hard rock pillar," Rock Mechanics and Rock Engineering, vol. 24, no. 3, pp. 155-166, 1991.

[24] X. R. Liu, X. Yang, and J. B. Wang, "A nonlinear creep model of rock salt and its numerical implement in FLAC ${ }^{3 \mathrm{D}}$," Advances in Materials Science and Engineering, vol. 2015, Article ID 285158, 8 pages, 2015.

[25] S. Q. Yang, P. Xu, P. G. Ranjith, G. F. Chen, and H. Jing, "Evaluation of creep mechanical behavior of deep-buried marble under triaxial cyclic loading," Arabian Journal of Geosciences, vol. 8, no. 9, pp. 6567-6582, 2015.

[26] X. J. Liu and Y. X. Zhang, "Analysis of reasonable excavation sequence and stress characteristics of portal section of shallow tunnel with unsymmetrical loadings," Chinese Journal of Rock Mechanics and Engineering, vol. 30, supplement 1, pp. 30663073, 2011 (Chinese).

[27] F. C. Xue, J. L. Ma, L. P. Yan, and Y. M. Zhao, “Three-dimension FEM analysis of large cross-section tunnel in collapsible loess constructed by CRD method," in Proceedings of the GeoFlorida, Advances in Analysis, Modeling, and Design, pp. 2349-2358, ASCE, West Palm Beach, Fla, USA, February 2010.

[28] H. J. Li, "Study on construction technology for tunneling in the plateau permafrost region," in Proceedings of the 14th Conference on Cold Regions Engineering, pp. 16-21, ASCE, Duluth, Minn, USA, August-September 2009.

[29] ISRM International Society for Rock Mechanics, Rock Characterization, Testing and Monitoring. ISRM Suggest Methods, Pergamon Press, London, UK, 1981.

[30] E. Hoek, C. Carranza-Torres, and B. Corkum, "The HoekBrown failure criterion-2002 edition," in Proceedings of the 5th North American Rock Mechanics Symposium and 17th Tunneling Association of Canada Conference (NARMS-TAC '02), pp. 267271, Toronto, Canada, 2002.

[31] M. Huang, Study on the creep properties of water-bearing siltite and its application in soft rock tunnel engineering [Ph.D. thesis], Chongqing University, Chongqing, China, 2010 (Chinese). 

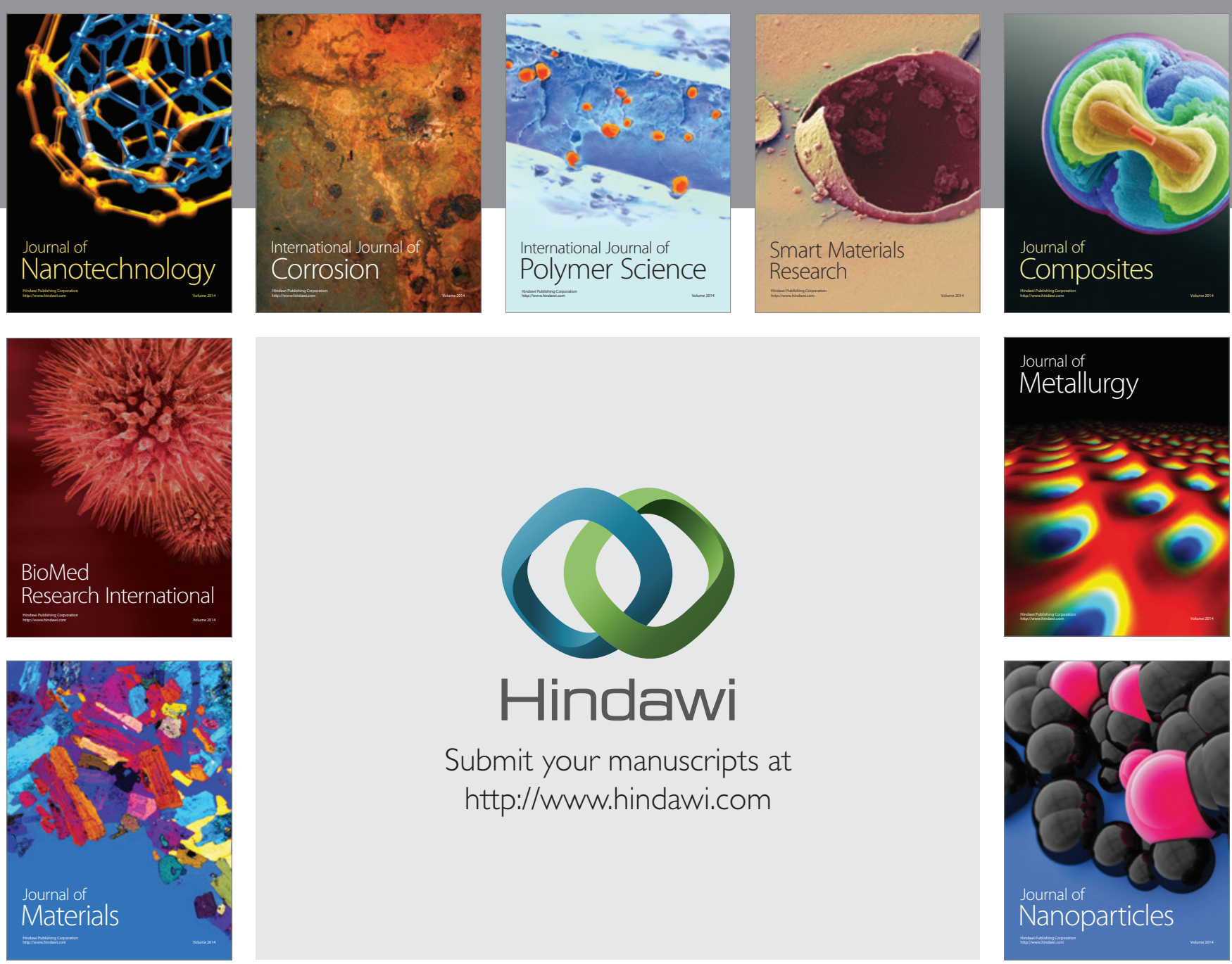

Submit your manuscripts at http://www.hindawi.com
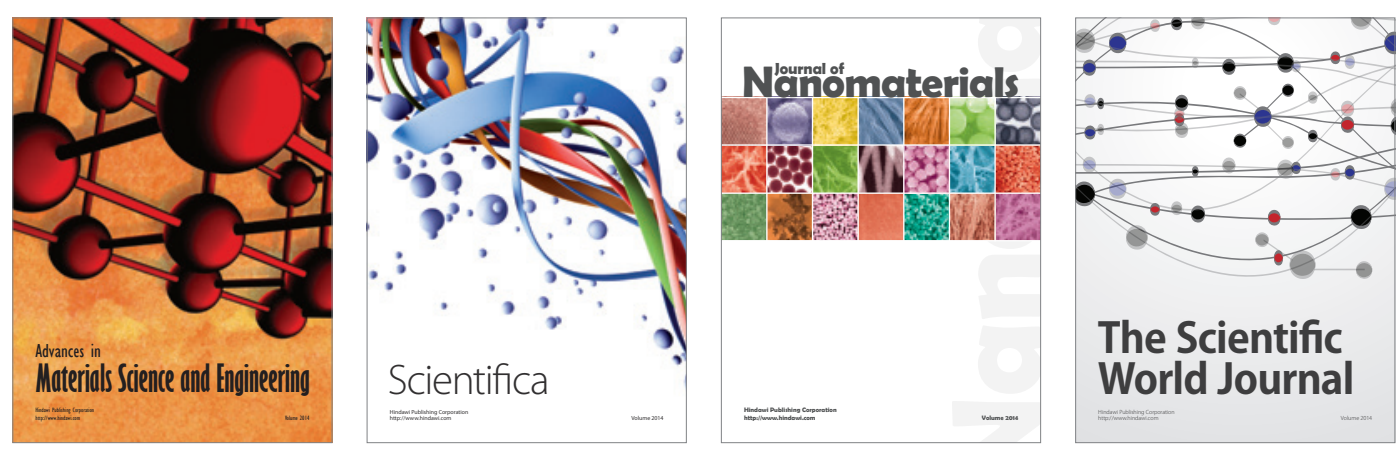

\section{The Scientific World Journal}
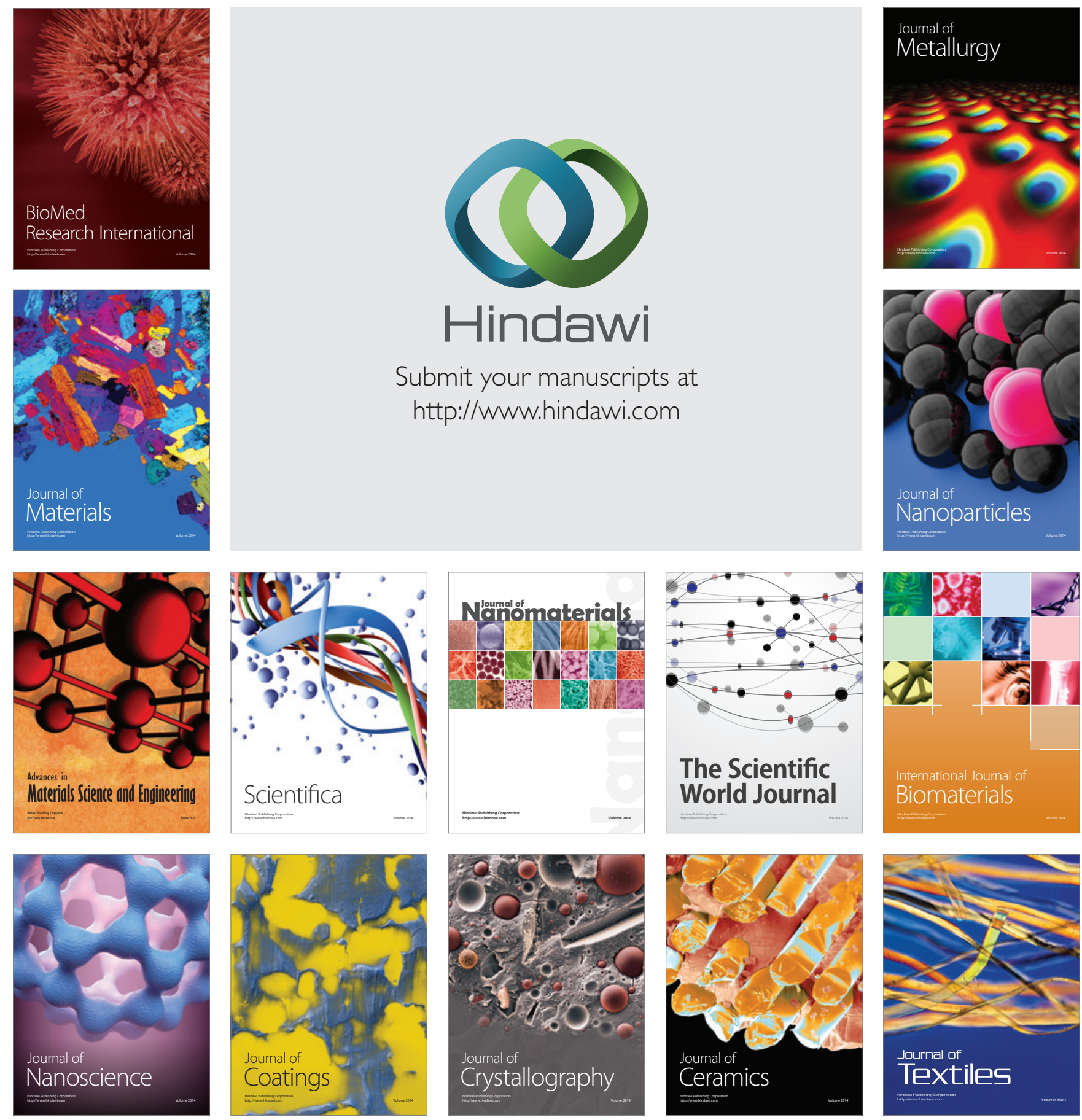